\title{
"What is the score?" A review of football-based public mental health interventions
}

\author{
Bettina Friedrich and Oliver John Mason
}

\author{
Bettina Friedrich is a Research \\ Associate at the Research \\ Department for Clinical, \\ Educational and Health \\ Psychology, University College \\ London, London, UK. \\ Oliver John Mason is a \\ Senior Lecturer at the Research \\ Department for Clinical, \\ Educational and Health \\ Psychology, University College \\ London, London, UK and is at \\ the School of Psychology, \\ University of Surrey, \\ Guildford, UK.
}

Received 15 March 2017 Revised 18 July 2017 Accepted 26 July 2017 (c) Bettina Friedrich and Oliver John Mason. Published by Emerald Publishing Limited. This article is published under the Creative Commons Attribution (CC BY 4.0) licence. Anyone may reproduce, distribute, translate and create derivative works of this article (for both commercial \& non-commercial purposes), subject to full attribution to the original publication and authors. The full terms of this licence may be seen at http://creativecommons. org/licences/by/4.0/legalcode

The authors thank Jessica Deighton for helpful comments on the manuscript. This study was funded by the National Institute for Health Research - School of Public Health Research (SPHR). Department of Health disclaimer: the views expressed are those of the authors and not necessarily those of the $\mathrm{NHS}$, the NIHR or the Department of Health. Grant holder is Dr Oliver Mason.

\begin{abstract}
Purpose - Football exercise as an intervention for people with severe mental health problems has seen an increasing interest in the past years. To date, there is, however, no comprehensive review of the empirical evidence regarding the effectiveness of these interventions. In this review, the authors have comprised the research findings from the peer-review literature as well as the theoretical approaches to football exercise as an adjunct treatment. This overview will be informative to everybody who is planning to develop a football intervention for this population as well as to the people who are preparing evaluation studies that measure the effectiveness of such interventions. The paper aims to discuss these issues.

Design/methodology/approach - The authors identified research papers in the peer-review literature that feature empirical findings on "football interventions" that aim at improving mental and/or physical well-being in participants with mental health problems. The authors are using the term "football intervention" here in the sense that the participants actively took part in football exercise, so the authors excluded studies in which the participants only watched football or used football as a metaphor to discuss mental health problems. In a table, the authors indicate the definition of the target group, targeted outcomes, measured outcomes, form and frequency of the intervention as well as the research method(s).

Findings - The authors identified 16 studies on 15 projects. The majority of studies were qualitative and had positive findings in which the participants reported increased well-being and connectedness, elevation of symptoms and improved physical well-being. The outcomes of the quantitative studies, however, were mixed with some results suggesting that not all intended goals were achieved. There seems to be a need for more quantitative studies to triangulate the qualitative findings. Interestingly, most interventions take place in the UK. Many studies fail to give detailed methodological information and often the aims of the interventions are vague or not stated at all.
\end{abstract}

Research limitations/implications - Due to the heterogeneity of the studies and relative scarcity of evaluation projects on football interventions for people with mental health problems, the authors could not conduct an in-depth systematic review. Furthermore, the information on methods was often unsatisfying and despite efforts to get more detailed input from the authors of cited papers, those gaps could not always be filled. Instead of coming up with a crystal-clear summary of whether and how football interventions work for everybody, topics were identified that need to be addressed in the planning of interventions, in evaluation studies, in implementation efforts and in the theoretical discourse.

Practical implications - This paper constitutes a helpful overview for everybody who is interested in the theoretical background of football interventions for people with mental health problems, for people who are planning to develop respective interventions, for researchers who engage in evaluation projects that look into the effectiveness of football interventions (or similar exercise interventions) as well as for the people who are interested in how football interventions can be implemented. This paper is likely to make a contribution to the advancement of alternative exercise interventions that aim at improving mental, physical and social health in people with mental health problems.

Social implications - This paper will help putting the topic of football interventions (and similar, alternative exercise interventions) further up on the public health agenda by providing an overview of the empirical evidence at hand and by specifying advantages of the approach as well as pointing out actions that need to be taken to make football a recognised, evidence based and viable option for adjunct mental health treatment that is attractive to potential participants as well as funders as well as to the potential participants.

Originality/value - There is no comprehensive summary to date that provides a (reasonably) systematic overview of empirical findings for football interventions for people with $\mathrm{MH}$ problems. Furthermore, the literature on the theoretical background of these interventions has been somewhat patchy and heterogonous. This paper aims at filling both these gaps and identifies the issues that need to be covered 
in the planning of respective interventions and evaluations. This paper will be useful to everybody who is developing football interventions (or similar alternative adjunct exercise interventions), who is conducting evaluation research in this area and who is interested in the implementation of football interventions.

Keywords Mental health, Inclusion, Evaluation, Football, Soccer, Physical activity

Paper type Literature review

With the increasing prevalence of mental health problems and thus growing burden on health systems (Mayor of London, 2014; McCrone et al., 2008), there is an increasing appetite for mental health interventions which complement "standard" or conventional treatment. In particular, "recovery-based" interventions outside mainstream psychiatric services that focus on the strengthening of people's abilities, gaining hope and social reconnection and empowerment are getting rising attention (Le Boutillier et al., 2015; Slade, 2009). Recovery interventions often focus on the principles of fostering inclusion and enhancing self-esteem through social activities and can be seen as a critical counter reaction to treatments that are strongly linked with the medical model of mental illness which advances biological treatments. In addition to this, the medical model is often seen as strongly deficit-oriented whereas approaches whose roots are often attributed to positive psychology usually focus more on the strengths in patients and ways of enhancing them (Seligman and Csikszentmihalyi, 2014).

A prominent group of recovery-focussed mental health interventions are based on sport or exercise activity, and some empirical evidence supports its effectiveness. Mood disorder is the most studied with Stathopoulou et al. (2006) concluding from meta-analysis of efficacy studies that "exercise can be a powerful intervention for clinical depression" (p. 188), leading to the suggestion that clinicians "consider adding exercise interventions to their armamentarium to strategies to help patients in distress" (p. 190). Schuch et al. (2016) have recently provided a systematic review of the impact of exercise interventions for people with depression. Exercise as an adjunctive mental health intervention has also been studied, albeit less frequently in aiding anxiety (see, e.g. Asmundson et al., 2013; Jayakody et al., 2013; Anderson and Shivakumar, 2015), self-esteem (Barton et al., 2012), schizophrenia (Faulkner and Sparkes, 1999; Carter-Morris and Faulkner, 2003; Campbell and Foxcroft, 2003) as well as general mood (Barton et al., 2012; Powers et al., 2015). Mechanisms of clinical change have also been the focus of qualitative enquiry such as the narratives of three men with schizophrenia engaging in physical activity (Carless and Sparkes (2008). Mason and Holt (2012a) reviewed the qualitative literature to identify the mechanisms in which participants with mental health problems benefit from mental health interventions and described a range of physical, psychological and social mechanisms that may explain the impact of exercise interventions for people with mental health problems.

Interventions aimed at improving the physical health in people with mental health problems are not only important in terms of supporting psychosocial recovery, but also to address the particular physical health needs in this population with cardiovascular vulnerabilities high on the list. Osborn (2001), for example, has argued that since morbidity and mortality rates are high in people with psychiatric problems, programmes aiming at improving the physical health are crucial though hitherto far too neglected.

Football, or "soccer" in some cultures, has gained a lot of attention in terms of being a popular tool for exercise interventions for people with mental health problems (for reviews, see Spandler and Mckeown, 2012; Darongkamas et al., 2011). There are several reasons for its popularity beyond its obvious appeal as a mass participation sport engaging one in five adults in England. We now explore some of the benefits for physical health, mental and social health triggered by football as an intervention, and why it may be well suited to some under-reached parts of the population.

\section{What makes football a suitable intervention for people with mental health problems?}

\section{"Match fit?" Physical health}

Oja et al. (2015) conducted a systematic review in which they compared the outcomes of different sports disciplines with regard to physical health benefits. The authors found that football was one of the disciplines that are most beneficial to the participants in terms of physical health 
improvements, including aerobic fitness, cardiovascular function, metabolic fitness and running performance. Krustrup et al. $(2013,2014)$ have also provided empirical evidence for the valuable impact of football training with regard to cardiovascular functions, especially in untrained men (Krustrup et al., 2009). Given the fact that in particular cardiovascular functions are often impaired in people with mental health problems (Batelaan et al., 2016; Scott et al., 2016), football seems a very suitable form of exercise intervention in this population.

\section{"Getting a kick out of it": mental health}

Battaglia et al. (2013), among others, argue that, in addition to the physical benefits of exercise, many psycho-educational and social characteristics of football practice are highly relevant to participants' lives: "[...] it is important to acknowledge the positive effects derived from the inner features of team activities, such as social and motivational opportunities, when soccer is employed to increase mental health; examples of these effects include having opportunities of social interaction, cooperating with others, respecting rules, acquiring other skills suitable for everyday life, sharing leisure experience, experiencing personal achievement, being part of a winning team, and receiving encouragement of other people with the same disorder" (p. 596).

Nielsen et al. (2014) used self-determination theory (Ryan and Deci, 2000; Deci and Ryan, 1985) to explain why participants are "intrinsically motivated" to participate in football exercise. According to the theory, people have an intrinsic need for autonomy, competence and relatedness and they will feel intrinsically motivated to partake in activities that fulfil these needs. Nielsen et al. (2014) argue that football as a team sport is more suitable to fulfil these essential needs and that it is therefore that participants feel more rewarded, arguing: "[...] the higher frequency of social interactions in the football activity creates more positive perceptions of social relations which in turn increase intrinsic motivation and ultimately adherence" (p. 73). Seime and Vickers (2006) similarly emphasise the importance of football's potential to trigger intrinsic motivation to exercise in people with depression; noting that finding the motivation and drive to do sports activity can be a hurdle for this population. Extending the traditional conception of what sport may offer in "Just a Game? The Therapeutic Potential of Football", Steckley (2005) explored the possibilities of using football as therapeutic intervention for young people in residential care. She suggested that football provides structure, contributes to the development of pro-social values and behaviour and can instil a sense of mastery and self-value in participants. Furthermore, recent research has shown that football can also be beneficial to cognitive functioning in the participants. Alesi showed that children who participate in football training had increased spatial organisation (Alesi et al., 2015) as well as increased agility, visuo-spatial working memory, attention, planning and inhibition skills (Alesi et al., 2016).

\section{"A place on the team": social inclusion}

Football has the clear potential to increase mental well-being by fostering interaction with others and training or rehabilitating social skills, enabling social inclusion. The effects on individual wellbeing are hard to disentangle from these social effects as these are interdependent to a large degree. Many people with (severe) mental health problems experience isolation (Brophy and Harvey, 2011) for a range of reasons: they drop out of the labour market (Perkins and Rinaldi, 2002); experience breakdown of meaningful social relationships; and also feel isolated as a consequence of experiencing mental health-related stigma and discrimination (Hinshaw, 2009; Link et al., 2001) and/or self-stigma (Link et al., 2001; Corrigan and Watson, 2002). Public health interventions are well placed to tackle several of these consequences with socially highly valued activities such as football prominent among them. For individuals often solely identified by their mental health problems whereby they are very devalued by society at large (e.g. as a "schizophrenic"), the potential for football to offer a degree of perceived social status and normalcy is considerable.

Darongkamas et al. (2011, p. 20) make it clear that perceived inclusion is a fundamental part of the effect of football interventions on mental well-being: '[...] benefits to participants' mental health and social and family life were the result of, or mediated by, meeting other people in a similar situation. This may have had the effect of increasing a sense of belonging, community and 
acceptance, which are all principles of social inclusion". In an ethnographic study of a communitybased team of service users, Mynard et al. (2009) underline the importance of the intervention's ability to meet the patients' psychosocial needs. Entitled using Liverpool supporters' famous chant "You will never walk alone [...]", McKeown et al.'s (2015) study in the North West of England explores football's quality to unify "in acts of solidarity and togetherness". Some argue that football has the power to bring people together from different backgrounds: "Significantly, it is the ability of football to 'reach' so many people that makes it a true game for all, irrespective of gender, age, ethnicity, religious belief, disability, socio-economic or health status" (Parnell and Richardson, 2014, p. 823).

\section{The attraction of football to young men}

It is a particular asset of football and football-based interventions that it is popular among a demographic which is often considered "hard to reach" in the context of mental health interventions: young men across a range of social, class and ethnic backgrounds (Mellor, 2008; Parnell and Richardson, 2014). Despite the high prevalence of mental health issues in young men, they remain reluctant to engage with statutory mental health services (Prior, 1999; Oliver et al., 2005). The fact therefore that football is an attractive activity and "hook" for this demographic makes is an interesting tool for engagement. In their analysis of the effectiveness of the "It's a Goal" intervention, Pringle, Zwolinsky, McKenna, Robertson, Daly-Smith, and White (2014), for example, point out the importance of this quality to football and how it makes it an important platform from which to reach out to men and encourage them to speak about and deal with mental health issues. Various high-profile professional footballers both with and without their own mental health issues have helped establish this platform in the media space, and more local initiatives have capitalised on it: "It's a Goal", for example, uses football metaphors to encourage men to open up and to speak about mental health problems and is an noteworthy example of how football as a "theme" can become of interest to men (Pringle, 2004; Spandler et al., 2013). According to Pringle (2004), it is not just the playing of football that can be a meaningful intervention in mental healthcare, but watching football or using football stadiums to host interventions can be similarly useful.

Robertson et al. (2013) also emphasise the fact that football is attractive for young men and make the important points that this bears the potential to be used intentionally as a means to engage them in positive health activities; the authors point out that rugby, for example, has been used as intervention for the same reason (Witty and White, 2011).

However, male role stereotyping, or "machismo", within football also has its downside as (Spandler et al., 2013) among others have pointed out. According to these authors, football and engaging with football overly emphasises the gender rules which might be counterproductive to therapeutic goals in the mental health intervention. This can create "paradoxical spaces" (Spandler and Mckeown, 2012) - while football is supposed to help men with opening up and with increase self-esteem, it runs the risk of replicating stereotypes and gender inequalities that play a negative role in men's health and social outcomes. Striving for dominance and experiencing respective performance pressure are, for example, such issues; the authors point out that football can be competitive and that it is "literally a game of winners and losers, in which one team succeeds at the others expense" (p. 141). This competitive side can potentially be counterproductive in the attempt to use football as a mental health intervention: "It is easy to see that the rules of football (emphasizing action, strength and competition) may conflict with the rules of therapy (favouring emotions, expression of vulnerability and concern)" (Spandler et al., 2014, p. 149). The potential effects of a more or less competitive atmosphere in such interventions depend of course on the personal preferences of the individual intervention participants. While the competitive element can be the main point of attraction to some as it provides them with an opportunity to prove themselves, it can be intimidating to others and can be considered as an unnecessary pressure by those who just want to "kick the ball" and who are more after an opportunity to socialise and get some physical exercise. There does not seem to be a "one size fits all" solution and it is important to bear these differences in individual preferences in mind when designing and implementing football interventions. Where possible, it might be worthy forming 
groups that feature different level of competitiveness and assign participants according to their personal preferences. Both male role stereotyping and competitiveness clearly need to be explicitly addressed within any football-based public health intervention to enable therapeutic possibilities for recovery. On a similar note, the level of physical exercise suitable for the participants has to be carefully considered. Given the increased prevalence of cardiovascular health issues in people with mental health problems, respective issues could be triggered or worsened by intense workout, so facilitators should be mindful of these issues and - where necessary - should monitor cardiovascular health in participants.

Despite these issues, there is an array of arguments that speak in favour of the suitability of football for an exercise-based adjunct public health intervention as outlined above.

\section{Empirical evidence}

What empirical evidence to date has examined the effectiveness of football interventions in a mental health context? Some years ago, Pringle (2009) suggested that "the challenge for those involved in football and mental health work is to begin to develop a body of evidence that stands up to scrutiny when commissioners and service planners suggest that "this is all a bit of a jolly really" and that staff should "get on with their real work". The main objective of this review is to provide an overview of the current empirical evidence regarding the benefits of football interventions for those with mental health problems.

Table I shows an overview of published studies identified by systematic search. We explored the available literature using the search engines Web of Science and Google Scholar. We entered search terms "(Football OR Soccer) AND (Mental disorder OR depress* OR psychiatr $\left.{ }^{\star}\right) "$. We included literature which describes football as an active intervention (i.e. actively played by the participants); for people who have mental health problems; that included empirical outcomes from quantitative and/or qualitative evaluation studies with any outcomes relevant to physical, mental and/or social health. We also used the bibliographies of all relevant literature to identify any further evaluation studies. In addition to this, we searched online more widely for "football interventions" to identify any relevant projects that described evaluation work that might be relevant. We contacted several national mental health organisations in Europe, Australia and North America to identify any further football intervention evaluations, though no additional reports were identified. Reference to one study was provided by a reviewer of this paper. In total, 16 relevant studies were identified in the present overview.

One study reported on a scheme involving several sporting activities of which football was the majority activity (Butterly et al., 2006). It is impossible to rule out other studies in which football is included but not explicitly described.

Unsurprisingly perhaps for such a diverse area of study, reports in the literature varied widely in the degree of description of the aims of evaluation, and the nature of the interventions. In constructing this overview, we attempted to identify, extract and summarise the most important information on the studies (see Table I).

The studies vary quite widely according to the participants targeted, the nature of the intervention and the methodologies employed. In terms of participants, some exclusively aim at those with severe and enduring mental health problems, with one occurring wholly in a rehabilitation context. Others are much more diverse in terms of mental health difficulties, even, in the case of "Imagine Your Goals", including around a third without mental health problems - something not explicitly envisaged at the outset of this very substantial programme in 16 professional clubs. Some schemes are exclusively male, while others have varying proportions of females. Some aim at younger participants, even with a particular "youth" focus, while others extend across the lifespan. In terms of setting, the most common was a football club, with both local and professional clubs represented. Many involved connections to participants via local mental health charities, statutory health and residential services.

Though it is somewhat difficult to be specific about the aims the commonest were increasing social contact/inclusion (seven schemes); improving physical health/fitness (six) and 


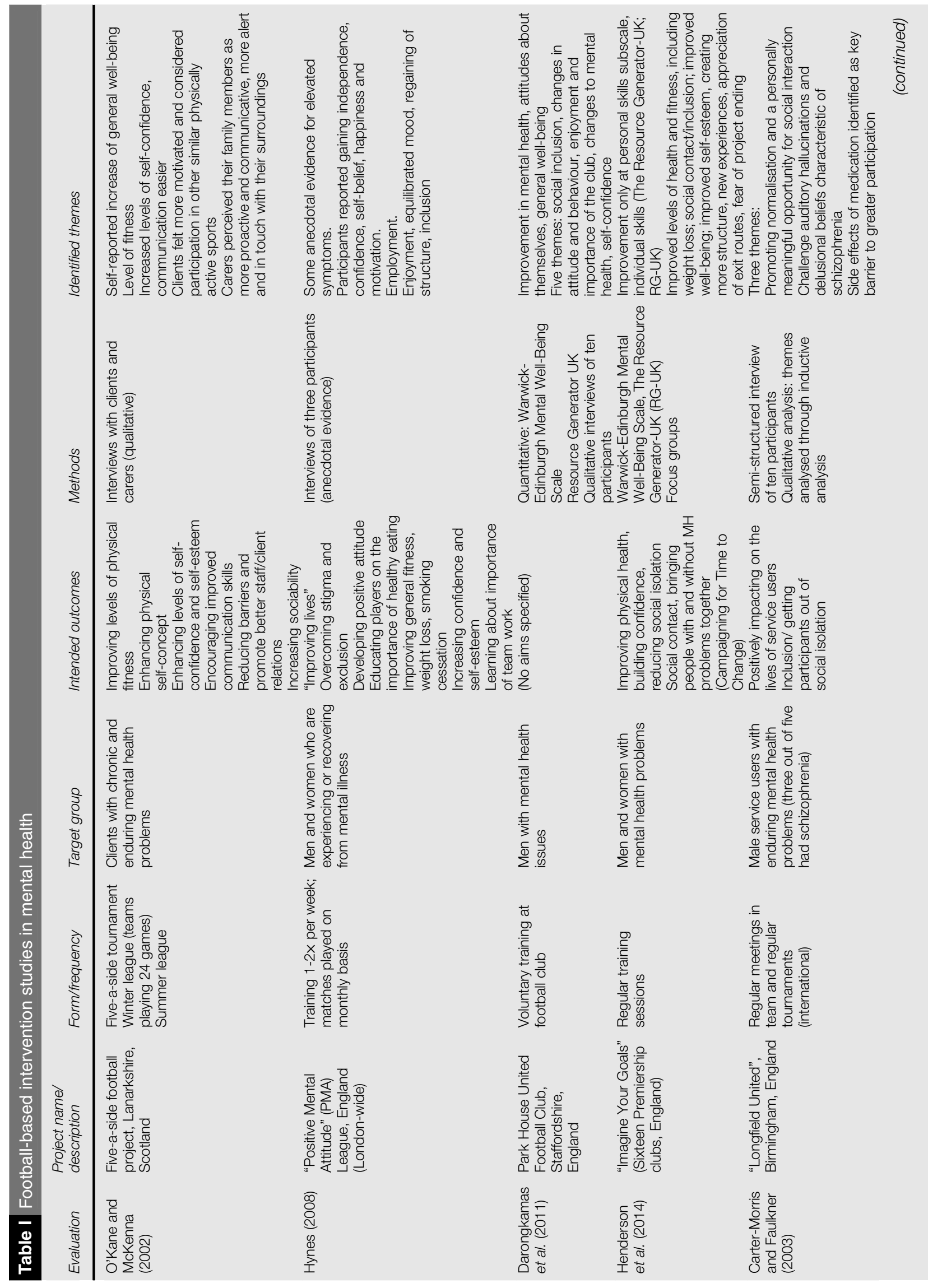




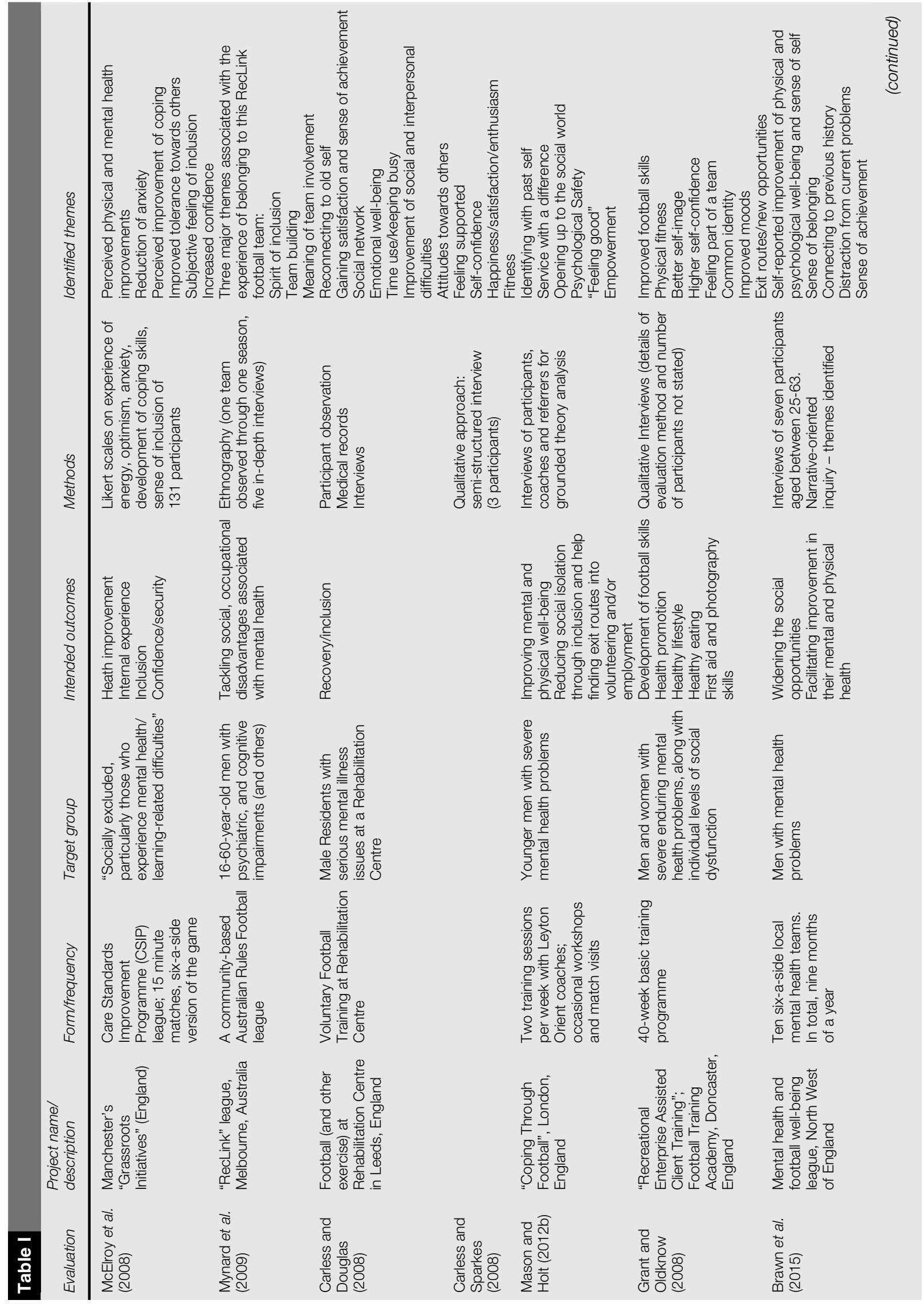




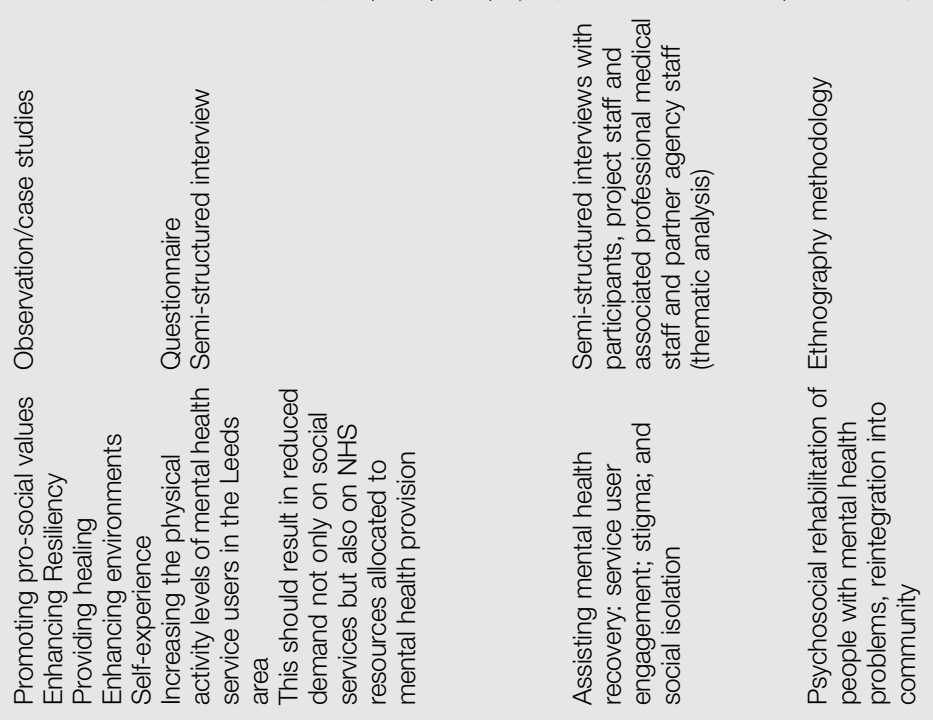

专画

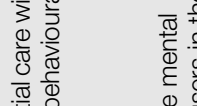

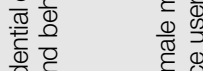

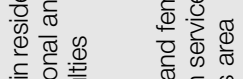

क을

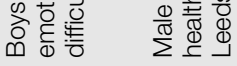

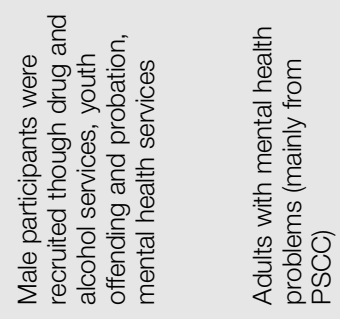

崩

은

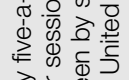

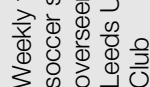

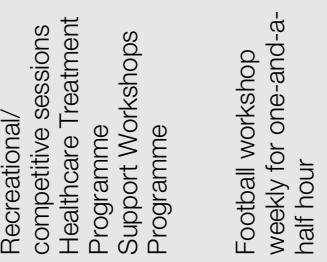

,

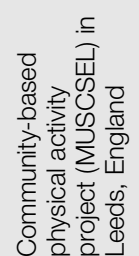

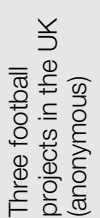

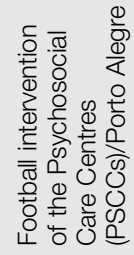

$\frac{\overline{0}}{\frac{0}{0}}$

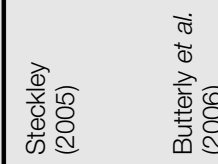

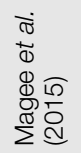

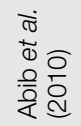


improving self-confidence (six). A minority of evaluations used quantitative indices with the Warwick-Edinburgh Mental Well-Being Scale being the most popular. The majority utilised a range of qualitative methods differing in their level of formality of data gathering and analytic methods (at least in the level of detail given).

The number of participants included in the evaluation studies varied widely. For example, Hynes (2008) conducted qualitative interviews with only three participants, while Henderson et al. (2014) had follow-up data on as many as 157 participants in their quantitative study. On a similar note, inclusion criteria of the interventions (and hence the respective evaluation) differed markedly. While Steckley's (2005) observation included boys from in residential care with emotional and behavioural problems, Grant and Oldknow (2008), for example, conducted an analysis on an intervention that include both male and female adult players with severe and enduring mental health problems. See Table I for details across the range of studies.

Due to the diversity of studies (aims, target groups, measures and outcomes) it is probably not appropriate to condense the findings into a single narrative: however, the empirical evidence thus far is universally encouraging. The majority of studies containing qualitative analysis have a high degree of consistency of thematic content. These themes can often be grouped into elevated self-esteem/empowerment/independence, emotional well-being/pleasure/enjoyment, the experience of inclusions/belonging/connecting and improvement of physical well-being. Rather than narrowly targeting a single outcome, almost all report significant impacts on psychological, social and physical health. Quantitative data on the other hand is relatively scarce, and failed to reach significance level on a number of measures (see e.g. Henderson et al., 2014), though typically sample size and measure completion rates are, perhaps unsurprisingly, rather low. As most of these studies do not have a control group, it cannot be ruled out that some of the observed effects in the quantitative studies might be due to the concurrent therapy when football intervention was used as an adjunct treatment form. While Wood et al. (2005) point out that a lack of control group is common in rehabilitation studies, it would of course be desirable if future quantitative evaluations would use control groups to disentangle the effects of primary and adjunct treatment where feasible. In the meantime, qualitative studies should help better understanding the mechanisms behind impact of football interventions.

Interestingly the clear majority of these studies have been conducted in England, with two in Scotland and one in Australia. This might be due in part to the particular role football and football clubs play in the culture and everyday life in England. It would certainly be interesting to obtain more empirical evidence from similar projects in other countries in order to establish in how far popularity and impact of similar football interventions are comparable to the findings gathered in England.

\section{Discussion and outlook}

The synopsis of empirical evidence while supportive of football-based adjunct mental health interventions is far from conclusive due to the wide range of interventions and methods used in studies. As a minimum football seems to be a feasible and acceptable tool to many participants, particularly young men, with the aim of improving physical, mental and social well-being particularly suited to a public health context outside of a clinical setting where it has largely been employed to date.

In line with the recovery-based principles, interventions are not symptom- or deficit-focussed, instead aiming to improve overall quality of life of people experiencing mental health issues - tackling diverse challenges including social inclusion, stigma, physical health and feelings of empowerment, for example, that have the potential to make an immense difference for this group. In addition to the direct outcomes for the participants, it is at least plausible that mental health-related stigma can be decreased by showcasing the presence and abilities of people with mental health problems in the community through football exercise, tournaments and leagues. Furthermore, when these football events also involve members from the general 
public, these interventions can be seen as a type of social contact intervention that are a common tool in fostering inclusion as well as decreasing stigma (Evans-Lacko et al., 2013): football seems to have a very unifying character and indeed global popularity across a very wide range of ethnic communities. These characteristics may make it a suitable vehicle in different countries and ethnically diverse urban areas where increasing inclusion is paramount (Nathan et al., 2010).

Football, however, should not be seen as a "wonder drug" that can be expected to work universally and under all circumstances. Instead of using a one-size-fits-all approach, it is desirable for interventions to clearly define the target group, to assess abilities and needs of potential participants and to tailor form, intensity and frequency of the football intervention accordingly. One important issue, for example, is whether competitiveness or collaboration is desirable. While a sense of achievement might be engendered by stressing performance, success and defeating others this can be at the expense of greater anxiety, fear of failure and encouraging collaboration (see e.g. Steckley, 2005). Furthermore, gender issues can be a potential area of conflict (Spandler et al., 2014). Such issues need to be addressed in the planning stage and monitored during the course of interventions for those projects that involve both men and women. In general, it seems important to identify, address and monitor potential conflict issues. Especially when working with very vulnerable target groups, reasonable supervision and reliable monitoring (emotional and physical health status, group issues) would seem to be essential ingredients of a well-planned intervention, not just for evaluation purposes but in particular to prevent possible harm for the participants by the intervention. Lastly, and as importantly, defining the exact intended outcomes of the intervention (on both, a group and individual level) appears imperative. While this might seem fairly obvious, several studies omit details of the intervention or of intended outcomes. Defining clear aims does not only seem important for tailoring evaluations appropriately, but also to clarify what participants can expect perhaps giving them the opportunity to personalise their own goals in terms of fitness, participation or achievement off the pitch (e.g. exit routes into employment, training or voluntary work).

It is important to emphasise at this point that football interventions are seen by all studies as an adjunct rather than a replacement for formal mental health treatment. In the best possible scenario such interventions can help increase emotional well-being to the point that the participants might experience a reduced need for mental health treatment, particularly of an acute or involuntary nature. However, it would be naïve to assume that playing football can directly replace formal mental health treatment and/or need for medication, especially in groups with severe mental health problems.

So what needs to be done to help football, or indeed any physical exercise, to be recognised as a promising adjunct intervention? After reviewing the literature over a decade ago, Callaghan (2004) recognised that "exercise improves mental health and well-being, reduces depression and anxiety and enhances cognitive functioning. Although exercise seems to improve the quality of life of those living with mental health problems, its value is seldom recognized by mainstream mental health services" (p. 482). It is in the public health arena that football and other physical activity/exercise interventions are increasingly been developed, albeit often disconnected from statutory service provision, regulation and evaluation processes.

In order to be properly recognised as an effective adjunct treatment form in an era of evidencebased practice, it is imperative to have more - and more specific - empirical evidence with regard to the impact of these interventions. From a health policy perspective, this also includes studies that investigate their cost-effectiveness and uniqueness of contribution. Due to the potentially positive effects of football interventions (and other similar physical activity interventions for this matter) on mental, physical and social health, it is likely that an implementation of more adjunct treatments of this kind might prevent some of the financial burden caused by mental health problems (and related issues) on the welfare system and the medical services. More detailed information on the extent of the reduction of these extremely high economic health costs that might be achieved through such interventions would be very valuable to obtain in detailed cost-effectiveness analyses. Such data would be an asset in persuading policymakers and other stakeholders to support the development,

VOL. 16 NO. 42017 | JOURNAL OF PUBLIC MENTAL HEALTH $\mid$ PAGE 153 
implementation and further evaluation of football interventions. Furthermore, empirical evidence might also encourage further collaborations between football clubs and associations like FIFA and FA, for example, with intervention facilitators and researchers. The growing sense of social responsibility by football clubs (especially in England) can be used for the advantage of such interventions (Henderson et al., 2014).

Empirical evidence, however, is not just essential for persuading potential stakeholders, but - when done comprehensively - can elucidate the key ingredients for success. This might help in tailoring interventions and making them more effective in general, and for specific target groups. A very informative and insightful overview of what some experienced experts consider indispensable in football interventions and respective evaluations is offered by Pringle, Hargreaves, Lozano, McKenna and Zwolinsky (2014). Given the multiple targets of change, it is important that evaluation combines quantitative indices (e.g. physical health indicators, psychological scales) with qualitative approaches (e.g. interviews, focus groups, participatory observation, ethnography). Social desirability can be of bigger concern in qualitative approaches (Choy, 2014) and there is potentially a Hawthorne effect at play here (Sedgwick and Greenwood, 2015; Roethlisberger and Dickson, 2003) which might be stronger in the collection of data from interviews and focus groups than of survey data, for example. Outcome-based evaluation is a necessity here.

\section{Summary}

In summary, there is a growing evidence base that is broadly supportive of football-based public health interventions aimed at improving emotional, physical and social well-being in people with mental health problems. At present, this is largely qualitative and provides quite a detailed picture as to the perceived health and social benefits both by participants, health staff and other stakeholders. The majority reported positive outcomes in terms of self-esteem, social inclusion and emotional/physical well-being. It is very unclear, however, which interventions work, for whom they offer most benefit, and what are the most significant and enduring positive outcomes. All interventions operated in the non-profit or charity sector with some possessing links of varying formality with statutory health and social service providers. There is a clear need for greater quantitative evidence for this area of public health so as to gain a solid foundation with potential funders and other stakeholders. Health economic evaluation was notable by its absence and is also a major gap requiring attention for more widespread and enduring service development in this area.

\section{References}

Abib, L.T., Fraga, A.B. and Wachs, F. (2010), "The body practises concerning mental health: a football workshop capabilities and possibilities in a psychosocial care centre", Pensar a Prática, Goiânia, Vol. 13 No. 2, pp. 1-14.

Alesi, M., Bianco, A., Luppina, G., Palma, A. and Pepi, A. (2016), "Improving children's coordinative skills and executive functions: the effects of a football exercise program", Perceptual and Motor Skills, Vol. 122 No. 1, pp. 27-46.

Alesi, M., Bianco, A., Padulo, J., Luppina, G., Petrucci, M., Paoli, A., Palma, A. and Pepi, A. (2015), "Motor and cognitive growth following a Football Training Program", Frontiers in Psychology, Vol. 6, pp. 1-7.

Anderson, E. and Shivakumar, G. (2015), "Effects of exercise and physical activity on anxiety", Progress in Physical Activity and Exercise and Affective and Anxiety Disorders: Translational Studies, Perspectives and Future Directions, Vol. 4, pp. 46-9.

Asmundson, G.J., Fetzner, M.G., DeBoer, L.B., Powers, M.B., Otto, M.W. and Smits, J.A. (2013), "Let's get physical: a contemporary review of the anxiolytic effects of exercise for anxiety and its disorders", Depression and Anxiety, Vol. 30 No. 4, pp. 362-73.

Barton, J., Griffin, M. and Pretty, J. (2012), "Exercise-, nature- and socially interactive-based initiatives improve mood and self-esteem in the clinical population", Perspectives in Public Health, Vol. 132 No. 2, pp. 89-96. 
Batelaan, N.M., Seldenrijk, A., Bot, M., Van Balkom, A.J. and Penninx, B.W. (2016), "Anxiety and new onset of cardiovascular disease: critical review and meta-analysis", The British Journal of Psychiatry, Vol. 208 No. 3, pp. 223-31.

Battaglia, G., Alesi, M., Inguglia, M., Roccella, M., Caramazza, G., Bellafiore, M. and Palma, A. (2013), "Soccer practice as an add-on treatment in the management of individuals with a diagnosis of schizophrenia", Neuropsychiatric Disease and Treatment, Vol. 9, pp. 595-603.

Brawn, P., Combes, H. and Ellis, N. (2015), "Football narratives: recovery and mental health", The Journal of New Writing in Health and Social Care, Vol. 2 No. 1, pp. 30-46.

Brophy, L. and Harvey, C. (2011), "Social isolation in people with mental illness", Medicine Today, Vol. 12 No. 10, pp. 73-8.

Butterly, R., Adams, D., Brown, A. and Golby, J. (2006), "Client perceptions of the MUSCSEL project: a community-based physical activity programme for patients with mental health problems", Journal of Public Mental Health, Vol. 5 No. 4, pp. 45-52.

Callaghan, P. (2004), "Exercise: a neglected intervention in mental health care?", Journal of Psychiatric and Mental Health Nursing, Vol. 11 No. 4, pp. 476-83.

Campbell, P. and Foxcroft, D. (2003), "Exercise therapy for schizophrenia”, Cochrane Database of Systematic Reviews, Vol. 4, pp. 1-8.

Carless, D. and Douglas, K. (2008), "The role of sport and exercise in recovery from serious mental illness: two case studies", International Journal of Men's Health, Vol. 7 No. 2, pp. 137-56.

Carless, D. and Sparkes, A.C. (2008), "The physical activity experiences of men with serious mental illness: three short stories”, Psychology of Sport and Exercise, Vol. 9 No. 2, pp. 191-210.

Carter-Morris, P. and Faulkner, G. (2003), "A football project for service users: the role of football in reducing social exclusion", Journal of Mental Health Promotion, Vol. 2, pp. 24-30.

Choy, L.T. (2014), "The strengths and weaknesses of research methodology: comparison and complimentary between qualitative and quantitative approaches", IOSR Journal of Humanities and Social Science, Vol. 19 No. 4, pp. 99-104.

Corrigan, P.W. and Watson, A.C. (2002), "The paradox of self-stigma and mental illness", Clinical Psychology: Science and Practice, Vol. 9 No. 1, pp. 35-53.

Darongkamas, J., Scott, H. and Taylor, E. (2011), "Kick-starting men's mental health: an evaluation of the effect of playing football on mental health service users' well-being", International Journal of Mental Health Promotion, Vol. 13 No. 3, pp. 14-21.

Deci, E.L. and Ryan, R.M. (1985), "The general causality orientations scale: self-determination in personality", Journal of Research in Personality, Vol. 19 No. 2, pp. 109-34.

Evans-Lacko, S., Malcolm, E., West, K., Rose, D., London, J., Japhet, S., Little, K., Henderson, C. and Thornicroft, G. (2013), "3016 - How can we use social contact interventions to reduce stigma and discrimination against people with mental health problems?", European Psychiatry, Vol. 28.

Faulkner, G. and Sparkes, A. (1999), "Exercise as therapy for schizophrenia: an ethnographic study", Journal of Sport and Exercise Psychology, Vol. 21 No. 1, pp. 52-69.

Grant, G. and Oldknow, H. (2008), "Does joining a football academy help mental health recovery?", Mental Health Nursing, Vol. 28 No. 2, pp. 8-11.

Henderson, C., O'Hara, S., Thornicroft, G. and Webber, M. (2014), "Corporate social responsibility and mental health: the Premier League football imagine your goals programme", International Review of Psychiatry, Vol. 26 No. 4, pp. 460-6.

Hinshaw, S.P. (2009), The Mark of Shame: Stigma of Mental Illness and an Agenda for Change, Oxford University Press, New York, NY.

Hynes, J. (2008), "The Positive Mental Attitude (PMA) Football League”, A Life in the Day, Vol. 12 No. 3, pp. 6-10.

Jayakody, K., Gunadasa, S. and Hosker, C. (2013), "Exercise for anxiety disorders: systematic review”, British Journal of Sports Medicine, pp. 1-11, doi: 10.1136/ bjsports-2012-091287. 
Krustrup, P., Hansen, P.R., Nielsen, C.M., Larsen, M.N., Randers, M.B., Manniche, V., Hansen, L., Dvorak, J. and Bangsbo, J. (2014), "Structural and functional cardiac adaptations to a 10-week school-based football intervention for 9-10-year-old children”, Scandinavian Journal of Medicine \& Science in Sports, Vol. 24, pp. 4-9.

Krustrup, P., Nielsen, J.J., Krustrup, B.R., Christensen, J.F., Pedersen, H., Randers, M.B., Aagaard, P., Petersen, A.-M., Nybo, L. and Bangsbo, J. (2009), "Recreational soccer is an effective health-promoting activity for untrained men”, British Journal of Sports Medicine, Vol. 43 No. S1, pp. 825-31.

Krustrup, P., Randers, M.B., Andersen, L.J., Jackman, S.R., Bangsbo, J. and Hansen, P.R. (2013), "Soccer improves fitness and attenuates cardiovascular risk factors in hypertensive men", Medicine \& Science in Sports Exercise, Vol. 45 No. 3, pp. 553-60.

Le Boutillier, C., Chevalier, A., Lawrence, V., Leamy, M., Bird, V.J., Macpherson, R., Williams, J. and Slade, M. (2015), "Staff understanding of recovery-orientated mental health practice: a systematic review and narrative synthesis", Implementation Science, Vol. 10 No. 1, pp. 1-14.

Link, B.G., Struening, E.L., Neese-Todd, S., Asmussen, S. and Phelan, J.C. (2001), "Stigma as a barrier to recovery: the consequences of stigma for the self-esteem of people with mental illnesses", Psychiatric Services, Vol. 52 No. 12, pp. 1621-6.

McCrone, P.R., Dhanasiri, S., Patel, A., Knapp, M. and Lawton-Smith, S. (2008), Paying the Price: The Cost of Mental Health Care in England to 2026, King's Fund, London.

McElroy, P., Evans, P. and Pringle, A. (2008), "Sick as a parrot or over the moon: an evaluation of the impact of playing regular matches in a football league on mental health service users", Practice Development in Health Care, Vol. 7 No. 1, pp. 40-8.

McKeown, M., Roy, A. and Spandler, H. (2015), "'You'll never walk alone': supportive social relations in a football and mental health project", International Journal of Mental Health Nursing, Vol. 24 No. 4, pp. 360-9.

Magee, J., Spaaij, R. and Jeanes, R. (2015), “It's recovery united for me': promises and pitfalls of football as part of mental health recovery", Sociology of Sport Journal, Vol. 32 No. 4, pp. 357-76.

Mason, O.J. and Holt, R. (2012a), "Mental health and physical activity interventions: a review of the qualitative literature", Journal of Mental Health, Vol. 21 No. 3, pp. 274-84.

Mason, O.J. and Holt, R. (2012b), "A role for football in mental health: the coping through football project”, The Psychiatrist, Vol. 36 No. 8, pp. 290-3.

Mayor of London (2014), London Mental Health. The Invisible Costs of Mental III Health, Greater London Authority, London.

Mellor, G. (2008), "The Janus-faced sport': English football, community and the legacy of the 'third way'”, Soccer \& Society, Vol. 9 No. 3, pp. 313-24.

Mynard, L., Howie, L. and Collister, L. (2009), "Belonging to a community-based football team: an ethnographic study", Australian Occupational Therapy Journal, Vol. 56 No. 4, pp. 266-74.

Nathan, S., Bunde-Birouste, A., Evers, C., Kemp, L., MacKenzie, J. and Henley, R. (2010), "Social cohesion through football: a quasi-experimental mixed methods design to evaluate a complex health promotion program", BMC Public Health, Vol. 10 No. 1, pp. 1-12.

Nielsen, G., Wikman, J.M., Jensen, C.J., Schmidt, J.F., Gliemann, L. and Andersen, T.R. (2014), "Health promotion: the impact of beliefs of health benefits, social relations and enjoyment on exercise continuation", Scandinavian Journal of Medicine \& Science in Sports, Vol. 24 No. S1, pp. 66-75.

O'Kane, P. and McKenna, B. (2002), "Five a side makes a difference", Mental Health Nursing, Vol. 22 No. 5, pp. 6-9.

Oja, P., Titze, S., Kokko, S., Kujala, U.M., Heinonen, A., Kelly, P., Koski, P. and Foster, C. (2015), "Health benefits of different sport disciplines for adults: systematic review of observational and intervention studies with meta-analysis", British Journal of Sports Medicine, Vol. 49, pp. 434-40.

Oliver, M.I., Pearson, N., Coe, N. and Gunnell, D. (2005), "Help-seeking behaviour in men and women with common mental health problems: cross-sectional study", The British Journal of Psychiatry, Vol. 186 No. 4, pp. 297-301.

Osborn, D.P. (2001), "The poor physical health of people with mental illness", Western Journal of Medicine, Vol. 175 No. 5, pp. 329-32. 
Parnell, D. and Richardson, D. (2014), "Introduction”, Soccer \& Society, Vol. 15 No. 6, pp. 823-7.

Perkins, R. and Rinaldi, M. (2002), "Unemployment rates among patients with long-term mental health problems", The Psychiatrist, Vol. 26 No. 8, pp. 295-8.

Powers, M.B., Asmundson, G.J. and Smits, J.A. (2015), "Exercise for mood and anxiety disorders: the state-of-the science", Cognitive Behaviour Therapy, Vol. 44 No. 4, pp. 237-9.

Pringle, A. (2004), "It's a goal!: Basing a community psychiatric nursing service in a local football stadium", The Journal of The Royal Society for the Promotion of Health, Vol. 124 No. 5, pp. 234-8.

Pringle, A. (2009), "The growing role of football as a vehicle for interventions in mental health care", Journal of Psychiatric and Mental Health Nursing, Vol. 16 No. 6, pp. 553-7.

Pringle, A., Hargreaves, J., Lozano, L., McKenna, J. and Zwolinsky, S. (2014), "Assessing the impact of football-based health improvement programmes: stay onside, avoid own goals and score with the evaluation!", Soccer \& Society, Vol. 15 No. 6, pp. 970-87.

Pringle, A., Zwolinsky, S., McKenna, J., Robertson, S., Daly-Smith, A. and White, A. (2014), "Health improvement for men and hard-to-engage-men delivered in English Premier League football clubs", Health Education Research, Vol. 29 No. 3, pp. 1-18.

Prior, P. (1999), Gender and Mental Health, Macmillan Press, Basingstoke and London.

Robertson, S., Zwolinsky, S., Pringle, A., McKenna, J., Daly-Smith, A. and White, A. (2013), "'It is fun, fitness and football really': a process evaluation of a football-based health intervention for men", Qualitative Research in Sport, Exercise and Health, Vol. 5 No. 3, pp. 419-39.

Roethlisberger, F.J. and Dickson, W.J. (2003), Management and the Worker, Psychology Press, London and New York, NY.

Ryan, R.M. and Deci, E.L. (2000), "Self-determination theory and the facilitation of intrinsic motivation, social development, and well-being", American Psychologist, Vol. 55 No. 1, pp. 68-78.

Schuch, F.B., Deslandes, A.C., Stubbs, B., Gosmann, N.P., da Silva, C.T.B. and de Almeida Fleck, M.P. (2016), "Neurobiological effects of exercise on major depressive disorder: a systematic review", Neuroscience \& Biobehavioral Reviews, Vol. 61, pp. 1-11.

Scott, K.M., Lim, C., Al-Hamzawi, A., Alonso, J., Bruffaerts, R., Caldas-de-Almeida, J.M., Florescu, S., De Girolamo, G., Hu, C. and De Jonge, P. (2016), "Association of mental disorders with subsequent chronic physical conditions: World Mental Health Surveys from 17 countries", JAMA Psychiatry, Vol. 73 No. 2, pp. 150-8.

Sedgwick, P. and Greenwood, N. (2015), "Understanding the Hawthorne effect", British Medical Journal, Vol. 351, pp. 1-2.

Seime, R.J. and Vickers, K.S. (2006), "The challenges of treating depression with exercise: from evidence to practice”, Clinical Psychology: Science and Practice, Vol. 13 No. 2, pp. 194-7.

Seligman, M.E. and Csikszentmihalyi, M. (2014), "Positive psychology: an introduction", Flow and the Foundations of Positive Psychology, Springer Netherlands, pp. 279-298.

Slade, M. (2009), Personal Recovery and Mental Illness, Cambridge University Press, Cambridge.

Spandler, H. and Mckeown, M. (2012), "A critical exploration of using football in health and welfare programs gender, masculinities, and social relations", Journal of Sport \& Social Issues, Vol. 36 No. 4, pp. 387-409.

Spandler, H., Mckeown, M., Roy, A. and Hurley, M. (2013), "Football metaphor and mental well-being: an evaluation of the It's a Goal! Programme", Journal of Mental Health, Vol. 22 No. 6, pp. 544-54.

Spandler, H., Roy, A. and Mckeown, M. (2014), "Playing by the rules? Gender relations in a football and mental health project”, The Journal of Men's Studies, Vol. 22 No. 2, pp. 140-54.

Stathopoulou, G., Powers, M.B., Berry, A.C., Smits, J.A. and Otto, M.W. (2006), "Exercise interventions for mental health: a quantitative and qualitative review", Clinical Psychology: Science and Practice, Vol. 13 No. 2 , pp. 179-93.

Steckley, L. (2005), “Just a game? The therapeutic potential of football”, Facing Forward: Residential Child Care in The 21st Century, Russell House Publishing, pp. 137-47. 
Witty, K. and White, A. (2011), "Tackling men's health: implementation of a male health service in a rugby stadium setting”, Community Practitioner, Vol. 84 No. 4, pp. 29-33.

Wood, A.M., White, I.R., Hillsdon, M. and Carpenter, J. (2005), "Comparison of imputation and modelling methods in the analysis of a physical activity trial with missing outcomes", International Journal of Epidemiology, Vol. 34 No. 1, pp. 89-99.

\section{About the authors}

Bettina Friedrich is a Research Associate at the Research Department of Clinical, Educational and Health Psychology, University College London. Bettina Friedrich is the corresponding author and can be contacted at: b.friedrich@ucl.ac.uk

Oliver John Mason is Senior Lecturer at the Research Department of Clinical, Educational and Health Psychology, University College London and Reader at the University of Surrey.

For instructions on how to order reprints of this article, please visit our website: 